\title{
Implicit memory: A commentary
}

\author{
HENRY L. ROEDIGER III \\ Rice University, Houston, Texas
}

\begin{abstract}
This commentary about implicit memory research deals with four issues: terminology, its underlying logic, cognate areas, and theoretical issues. First, although appropriate terms are still being developed to describe the phenomena of interest in this area, I advocate the explicit/implicit distinction for the different forms of memory and types of tests and argue that the term remembering should only be applied to explicit retention. Second, although discovering functional dissociations between two retention tests are a useful research tactic, I believe a better strategy is to use converging operations for theoretical constructs in the form of multiple tests. Third, implicit memory research should be informed by research on similar problems in other domains (e.g., motor skill learning, social cognition). Finally, if we accept the interpretation of explicit/implicit memory research in terms of memory systems, it appears that 5 major systems and 20 or so subsystems may be required. Historical analogues to this situation are briefly considered.
\end{abstract}

The field of inquiry now known as implicit memory research has a long history, as Daniel Schacter described briefly in his opening remarks to this symposium and more fully in his important review paper (Schacter, 1987). However, most experimental psychologists probably became aware of this new endeavor as a specific line of inquiry only in the 1980s. Papers such as those of Warrington and Weiskrantz $(1968,1970)$ may have been familiar to a few in the 1970 s, but more likely the important publications from several groups in the early 1980 s directed experimental psychologists' attention to this new line of work. I would include in this set of seminal papers those of Jacoby and Dallas (1981), Jacoby and Witherspoon (1982), Graf, Mandler, and Haden (1982), and Tulving, Schacter, and Stark (1982). All of these papers reported dissociations between two measures of memory-one explicit and one implicit-as a function of some experimental variable. Typically, the dissociation involved an independent variable that experimental psychologists thought they had pinned down reasonably well, such as levels of processing or retention interval. The remarkable finding from these new studies was that the "well-understood" variable did not have the usual effect on the implicit memory measure, and in some cases even had a reversed effect (Jacoby, 1983). These dissociations, coupled with similar dissociations from neuropsychological populations, excited the interest of experimental psychologists and eventually led to the current symposium.

The 1980s can be designated as the decade in which implicit memory research became a separate subtopic in

I thank James Neely, Daniel Schacter, Endel Tulving, and Michael Watkins for their comments on a prior draft of this article, and Suparna Rajaram and Kavitha Srinivas for their help in preparing it. The author's address is Department of Psychology, Rice University, Houston, TX 77251-1892. the study of human memory. Nineteen eighty-nine may even be seen as a landmark year in its development. For one thing, this symposium at the Psychonomic Society provides a fitting capstone for the decade. Judging by the attendance (which I estimated at 300-400), the topic has wide interest. The second noteworthy event of 1989 was the publication of the first book with "implicit memory" in its title (Lewandowsky, Dunn, \& Kirsner, 1989).

My commentary is on the current status of some issues in the field, as reflected both in the foregoing papers in the symposium and in other recent developments. I shall briefly cover four topics: some issues of terminology, a brief critique of commonly accepted methods and the logic of inquiry in this area, a survey of cognate areas that need consideration, and finally a few remarks on theoretical developments, particularly about memory systems.

\section{Terminology}

It is no secret that the terminology in the inchoate area of implicit memory research is in a confusing state. For example, the term procedural memory seems to have three or four distinct meanings, depending upon the author using it. Even the contrast between explicit and implicit memory (Graf \& Schacter, 1985) is in dispute, with others preferring to use direct and indirect memory to refer to the same contrast between tests. As far as I can tell, Segal (1966) was the first to use the direct/indirect terminology, but the most recent champions have been Richardson-Klavehn and Bjork (1988), following Johnson and Hasher (1987). Schacter (1987) uses the implicit and explicit memory distinction to refer both to forms of memory and to two classes of memory tests (but not to different memory systems in the brain). RichardsonKlavehn and Bjork (1988) agree with the implicit/explicit usage for distinguishing forms of memory but, for various reasons, advocate the direct/indirect terminology in describing the two different classes of tests. 
This is not the place for a lengthy discussion of whether explicit/implicit or direct/indirect should be the preferred terminology for memory tests. Briefly, I opt for the former for several reasons. First, the explicit/implicit contrast seems to better reflect the notion of different "modes of retrieval" (to borrow the phrase I used with Blaxton in 1987), or different forms of memory. The explicit/implicit contrast implies that access to memory operates differently in the two cases. On the other hand, the contrast between direct and indirect tests seems to imply that the same knowledge or form of memory is being accessed, but directly in one test and indirectly in the other. If this is so, strong ("crossover") dissociations between these two types of tests would not be expected. In short, the fact that the tests access different forms of memory should guide our use of terms in describing them.

A more pragmatic reason for favoring the explicit/implicit terminology for tests can be illustrated by some difficulties of exposition that Brad Challis and I have recently encountered in preparing a manuscript (Roediger \& Challis, 1990). Briefly, part of the paper is devoted to the issue of whether or not priming on a word-fragmentcompletion test ( $-1_{-}$ha $\left._{-}\right)$is affected by prior study of the target word (elephant) or of its synonyms and associates (pachyderm, tusk). Following the widely accepted terminology introduced by Cofer (1967), the former case is often referred to as direct priming and the latter case as indirect priming. If this terminology is continuedand I think it should be-then writing a paper about whether direct and indirect priming occurs for direct and indirect memory tests can be somewhat confusing, as Challis and I discovered. We quickly switched to the explicit/implicit test contrast. ${ }^{1}$

The possibility exists that neither the explicit/implicit nor the direct/indirect contrast will wind up being the accepted terminology, because many researchers complain (at least privately) about both sets of terms. Other terms have been suggested (e.g., see Jacoby \& Witherspoon, 1982). Perhaps a more accurate pair of descriptors would be retention with awareness and retention without awareness. Although these are longer and clumsier, they accurately capture the relevant contrast better than do the other two sets of terms. Of course, the thorny problem of assessing awareness and its implications must be overcome, but good conceptual progress has been made on this front (Schacter, Bowers, \& Booker, 1989).

The fact that we have not yet straightened out our terminology in 1990 is, in my opinion, no cause for despair. We are currently trying out a number of terms, and some will emerge in the years to come as the most useful. At this point, we may not even know enough about the phenomena to invent the best descriptors. However the terminology develops, I would like to conclude this section by making one strong recommendation concerning use of the term remember and its related forms, following the lead of Tulving (1985). According to common usage and most dictionary definitions, remembering implies that a person is consciously aware of the knowledge from past experience being brought to mind at a later time.
Thus, the term should be used exclusively for explicit (or direct) forms of retention. If we retain this assumption, the phrase "remembering without awareness" is properly seen as an oxymoron, as is the phrase "implicit remembering." I think we should drop all of these contradictory uses; retention without awareness, yes, but remembering without awareness, no.

\section{Some Methodological Observations}

The logic of the typical experiment comparing explicit and implicit memory is straightforward and follows the logic of functional dissociation: manipulate an independent variable (or, in neuropsychological investigations, a subject variable) and observe subjects' performance on two different retention tests, one of each type. Depending upon one's theoretical orientation, the two tests could be considered as representing explicit and implicit tests, episodic and semantic tests, declarative and procedural tests, data-driven and conceptually driven tests, and so forth. When dissociations are found between tests as a function of the independent or subject variable of interest, the resulting pattern is seen as validating the theoretical contrast used in selection of the tests.

This logic is fine as far as it goes, and has led to many interesting and important discoveries. However, the limitations quickly become obvious. We find dozens of dissociations on all sorts of dimensions, but rarely do researchers provide converging operations to substantiate their theoretical constructs. I have made this point in a number of prior writings (starting with Roediger, 1984) but believe it needs reiteration. To put the matter briefly, in designing experiments to investigate dissociations between explicit and implicit measures of memory, we need to incorporate into our experiments multiple tasks thought to reflect the construct (Neely, 1989). If, for example, we believe that separate episodic and semantic memory systems underlie performance on these tests and can be dissociated by a particular variable, we need (minimally) two tasks in the experiment to reflect episodic memory and two other tasks to reflect semantic memory. In addition, for similar reasons, we also need to include multiple independent variables to assess whether the dissociations between tests generalize across this dimension (Shoben \& Ross, 1986).

The general idea is to manipulate independent variables of interest to see how they affect performance on (at least) two episodic tests and on two semantic tests. If the effect of the variables is the same on both of the episodic tests and on both of the semantic tests, but the pattern differs between tests falling into the different classes, then support for the theoretical distinction is warranted. On the other hand, following this strategy also leads to the possibility that dissociations will be found between implicit (or semantic) memory tests and between explicit (or episodic) memory tests. Indeed, Blaxton (1989) has recently reported just such a pattern with normal subjects, as have others (Srinivas \& Roediger, in press; Witherspoon \& Moscovitch, 1989). Butters's presentation in this symposium provides a compelling example of this strategy 
with various neuropsychological populations. Such dissociations between implicit tests show, minimally, that no single underlying theoretical construct can explain implicit retention (just as no single construct can explain explicit retention).

The general point is that there is nothing privileged about dissociations between explicit and implicit memory tests, and that a proper theory must take account of this fact. The explicit/implicit distinction is nonetheless important, because when test conditions are held constant except for the instructions subjects are given at the time of testing, dissociations between implicit and explicit tests can still be found in both normal and amnesic populations (as first shown by Graf \& Mandler, 1984, Experiment 3). The plea in this second part of my commentary, then, is for multiple converging measures of our theoretical constructs within the same experiment, or at least under similar conditions.

\section{Cognate Areas}

The study of implicit memory runs the risk of becoming an insulated enterprise. Although I argued above that this area has blossomed as an independent field of inquiry only in the 1980s, there are obviously many antecedents and many cognate areas that should be studied in parallel, with the hope for cross-fertilization of thought. I mention seven here, briefly.

First, Jacoby and Brooks (1984) have pointed to interrelations between the study of processes in concept formation and those in memory. Indeed, they have argued strongly that theories of memory must commit themselves to a particular theory of concept formation. Many experimental problems in the study of concept formation are also similar to those in implicit retention, with transfer designs being frequently employed and researchers worrying about whether or not rules for defining concepts can be described in words.

A second parallel area, where the interrelations have also been developed by Jacoby (e.g., Jacoby \& Kelley, in press), is the fertile field of social cognition. Researchers have studied the effects of priming concepts, such as hostility and friendliness, in person perception (Smith \& Branscombe, 1988; Srull \& Wyer, 1980) and wondered whether the effects of past experience on current behavior are accessible to awareness (Nisbett \& Wilson, 1977). Again, many of the techniques bear a strong similarity to those used in studying implicit memory.

A third area that would seem directly related is the study of explicit and implicit processes involved in learning artificial grammars (e.g., see Reber, 1967). Indeed, the terms explicit and implicit were used in this literature long before the study of implicit memory by experimental psychologists began, although the terms have different shades of meaning in the two fields of inquiry. One interesting finding to emerge from studies of artificial grammar learning is that when subjects are told explicitly to search for rules when exposed to strings of letters, they show less learning of the rule used to generate the strings than when such instructions are omitted (see Reber, 1989). So far, there has been little cross-referencing of studies of implicit grammar learning and implicit memory.

A fourth potential area that deserves attention is the transfer-of-training literature that was such a hot topic in experimental psychology from (roughly) the 1940s to the 1960s. Researchers were interested in assessing how learning of one task had proceeded (or what had been learned) by transferring subjects to related tasks (e.g., see Hovland, 1951; Postman, 1971) and taking the amount of transfer to the new task as a reflection of the processes or contents of original learning. Of course, implicit memory measures are also transfer measures, and the formal logic (if not the procedural details) is quite similar to implicit memory studies and some of the older transferof-training experiments. Many of these prior findings may take on new importance if they were to be reexamined.

Fifth, students of implicit memory have paid surprisingly little attention to the work involved in learning motor skills. After all, the usual definition of procedural learning involves the running off of some skilled behavior, and most of the common examples given (riding a bicycle, serving a tennis ball) are motor skills. There is a rich body of literature on motor skill learning (e.g., Schmidt, 1988) that could be examined to good effect. In a related vein, some researchers have shown that complex rules relating stimuli to responses in choice reaction-time tasks can be learned implicitly (Lewicki, Czyzewska, \& Hoffman, 1987; Nissen \& Bullemer, 1987; Stadler, 1989). Again, transfer designs are critical in this literature too.

Sixth, the study of implicit memory also interrelates with studies of higher mental processes, particularly those involved in analogical transfer and problem solving. The issue is whether subjects who have learned to solve a particular sort of problem will be able to use the solution again when faced with another problem of a similar type. The general finding is that subjects fail to transfer knowledge from one problem to another unless they are either explicitly reminded at the time of the second problem about the original solution, or unless the surface similarity between the two problems is so great as to force such reminding (e.g., see Gick \& Holyoak, 1983; Holyoak, 1985). In short, transfer occurs under explicit (aware) test conditions, but not under implicit conditions. The issue researched is quite similar to that involved in conceptually driven implicit memory tests (Roediger, Weldon, \& Challis, 1989), such as prior priming of words on their later use in answering general-knowledge questions (see Blaxton, 1989). Indeed, the issue of transfer can be seen as even broader by asking how much of what is learned during some educational process can be transferred or generalized outside the educational context. Lehman, Lempert, and Nisbett (1988) have examined whether training in statistics provides better reasoning for solving statistical problems outside the context of a statistics course, which provides one example of a cognate area in education. Implicit transfer of knowledge from educational settings to others may provide an interesting topic for future research.

The last topic to be mentioned should, in some ways, have been the first: the study of perceptual processes. 
The last topic to be mentioned should, in some ways, have been the first: the study of perceptual processes. Some of us believe that many commonly used implicit memory tests rely heavily on bottom-up, data-driven processing and, thus, the study of perception is obviously critical. Indeed, psychologists studying perception have been interested in the phenomenon of perceptual priming for quite some time (Gollin, 1960; Leeper, 1935), an interest which continues to the present Psychonomic Society meeting in a paper by Biederman, Cooper, and Gerhardstein (1989; see also Biederman, 1987). Biederman is interested in the perception and recognition of objects, which relates to the implicit memory studies of picture fragment completion (e.g., Snodgrass, 1989; Weldon \& Roediger, 1987). More commonly, implicit memory studies involve resolving words from data-limited displays-either brief presentations or fragmented forms. The interrelations between this work and that in the study of word perception points to yet another critical area of overlap.

Schacter, Cooper, and Delaney, in the prior paper in this symposium (and 1990), and Tulving and Schacter (1990) have recently argued that a perceptual representation system-a newly discovered memory systemunderlies data-driven priming (see also Schacter, in press). The perceptual representation system may be what perception psychologists have been studying all along, although they simply call it "perception.", In short, to the extent that we study perceptual processes in implicit memory work, we need to be better acquainted with the basic research in perception.

\section{Theoretical Issues}

Numerous theories have been advanced to explain implicit memory phenomena and the relation between implicit manifestations of memory and explicit measures. Two general classes of theory have received the most attention: experimental psychologists have generally advocated some type of processing explanation of dissociations (e.g., Graf \& Mandler, 1984; Jacoby, 1988; Masson, 1989; Roediger et al., 1989), whereas those immersed in neuropsychology have favored interpreting the dissociations in terms of distinct memory systems in the brain (e.g., Sherry \& Schacter, 1987; Squire, 1987; Tulving, 1983; Weiskrantz, 1989). I confine my comments here to the latter.

The proposals for memory systems differ considerably in detail, but the guiding assumption is that the brain has distinct memory systems, and the theorist's job is to discover the number of independent systems and their interrelations in explaining how explicit and implicit memory phenomena occur. Two of my students and I have critiqued this approach to explaining memory phenomena (Roediger, Rajaram, \& Srinivas, in press), and have argued that the evidence currently available from studies of human memory does not fulfill the criteria proposed by Sherry and Schacter (1987) for postulating distinct memory systems. I do not have space to repeat the essence of the arguments here, but instead will relate an anecdote. We sent the chapter to a number of people for comments, in order to eliminate errors and (we hoped) to sharpen our logic. We got the longest response from Endel Tulving, and I appreciate his permission for quoting from the first part of a 3.5-page, single-spaced missive delivered by electronic mail.

First, let me tell you something that you may already suspect deep in your heart: The "battle" over multiple memory systems is over, and the multiple-systems view has won. Some people have not realized it yet, because they refuse to look at the global picture. And even after most have seen what happened, there will remain a few diehards-there are always some-who are going to their graves with the convictions that they inherited from their teachers in graduate school... The outcome was (or, for nonbelievers, is going to be) what it was, because the general idea of multiple memory systems fits the biological orientation of our day, and biology matters more than does psychology right now. Biologists eat and breathe specificity and modularity, and they think the idea of "unitary" memory, or unitary anything, is a philosophical affectation. It is as simple as that.

The guiding assumption of the last few sentences is certainly true. Neuropsychologists generally do "breathe specificity and modularity," as a reading of recent important texts in the area of cognitive neuropsychology clearly attests (Ellis \& Young, 1988; Shallice, 1988). The primary criterion for separating modules and systems is the logic of experimental dissociation, although its unbridled use in separating systems is not without its critics (e.g., Neely, 1989; Olton, 1989). However, for the moment let us leave such doubts aside and assume that dissociation experiments do reveal distinct systems or modules. How many memory systems might we need to postulate to account for dissociations in normal subjects and in neuropsychological patients in 1990 ?

In preparing to answer this question, I first paused to ask the question of how many memory systems had been postulated in 1975 on the basis of evidence available then. I came up with six: short-term and long-term stores (Atkinson \& Shiffrin, 1968), verbal and imaginal stores or systems (Paivio, 1969), and episodic and semantic memory (Tulving, 1972). These are not the only candidates, but they are the ones most widely discussed at that time.

Now, of course, the scene is quite different. Although some theorists have argued for a relatively small number of systems-with Tulving (1985) proposing three main systems, Squire (1987) arguing for two overarching systems, Tulving and Schacter (1990) for four-such ideas have been criticized for ignoring a good deal of neuropsychological evidence (Ellis \& Young, 1988, pp. 304306). Weiskrantz $(1987,1989)$, among others, has taken a broader look at the evidence in constructing a typology 
of memory systems, and his writings inspired the construction of Table 1, although the ideas of others are represented, too.

Although systems theorists are fond of saying that they are attempting a taxonomy of memory, the term collage seems more appropriate at the present stage of our knowledge. In constructing Table 1, I tried to err on the side of conservatism, but even so came up with five main systems and about 20 or so subsystems. A detailed examination of the neuropsychology of reading and understanding speech would lead to many more systems (e.g., see Ellis \& Young, 1988, p. 222). To reiterate, the configuration in Table 1 is my own, but it captures many of the ideas currently available in the neuropsychology literature (e.g., as summarized by Ellis \& Young, 1988). If my calculation is even in the right ballpark, then we have progressed from about 6 systems in 1975 to 20 or so today.

Table 1 is unsatisfying in certain aspects. For example, I have placed short-term memory as a subsystem in an episodic memory system, following common practice. Episodic or event memory is the system postulated as damaged in amnesic patients, but of course short-term memory is spared in them. This implies that short-term memory is not a subsystem of episodic memory and (within this framework) should not be considered a part of episodic memory. Perhaps it is a separate system. In-

Table 1

Memory Systems Collage

Episodic (event) memory systems
Short-term store
Visual
Auditory
Long-term store
Verbal
Visual (Imagery)
Knowledge systems
Lexical Systems
Visual
Input
Output
Auditory
$\quad$ Onput
Concrete/abstract
High frequency/low frequency
Visual objects
Faces
Meaning
$\quad$ Category specific
Modality specific
Pemantic systems
Procedural system
Motor skills
Cognitive skills
Structural description system (objects)
Prible associative memory systems
Classical conditioning
Perceptual representation system ('traceless QM system”')
Word-form system
Pystems

terestingly, the status of short-term memory as a preserved memory capacity in amnesic patients rarely figures in discussions of memory systems. Other problems of commission (is the priming word-form system the same as the visual input lexical system?) and omission (what about operant conditioning?) exist in Table 1, so it should be seen as quite tentative and incomplete.

Of course, I do not doubt that in a few years 20 will seem much too conservative an estimate for memory systems. Given the inventiveness of neuropsychologists and experimental psychologists, many more specific patterns of brain damage resulting in specific cognitive deficits will be found, and many more functional dissociations in normal subjects will be discovered, too. To provide just one example, in reading some recent neuropsychological literature, I was struck by an observation made by Gazzaniga (1989):

One patient, for example, was unable to name the color of fruits that were red. Thus, in response to the question, "What is the color of an apple?"' there was a chance performance. Yet, the same patient was easily able to name the color of a banana. Additionally, the same patient was easily able to name the color of fire engines and school houses. It is conceivable that her incapacity to identify the color of red fruits was due to crucial fibers being interrupted within her left hemisphere that connected together the appropriate information sources. (p. 949)

Apparently, these "crucial fibers" could be considered a very specific module, or cognitive system, or memory system: the red fruit system. Those proponents of extreme modularity of mind will probably be able to discover hundreds of similar systems.

The fact that the number of putative systems is increasing so rapidly provides some cause for concern to experimental psychologists, who prefer greater caution in these matters and would like to see rather more stringent criteria imposed before a new system is announced (Roediger et al., in press). But the sheer fact of increase does not mean the systems proposals are incorrect. After all, many parallel cases of increases in the number of entities exist in science-the number of elements in the periodic table, the number of stars and galaxies in the known universe, the known numbers of species of insects, the number of neurotransmitters, to provide just a few examples.

But the increase in the number of proposed psychological entities in many contexts has historically had a less certain outcome. The situation today in the study of memory systems has several parallels in the history of psychology. Before 1920, the Gestalt psychologists began discovering the Gestalt laws of perception that are familiar to all of us. What may be less familiar is how quickly the number grew. When Helson reviewed the literature in 1933, he identified 114 ! Of course, the exact number may still be debated, but no contemporary treatment provides anything like this number (most having been subsumed under more general laws). ${ }^{3}$

Another similar instance comes from the study of intelligence. Original factor-analytic studies seemed to show 
a general component of intelligence, but later Spearman proposed both a general component and specific components. Thurstone, factor analyzing his data and others', arrived at seven "primary mental abilities." The pace quickened somewhat over the years, for in Guilford's "dimensional structure of intelligence," 120 components were postulated (see Hilgard, 1987, for a review). The vehicle of progress in studying memory systems is the logic of functional dissociation rather than factor analysis, but the results seem the same-there are always more systems or factors. [With the advent of Robert Sternberg's (1988) triarchic theory of intelligence, we have recently been treated to a more manageable three.]

A final parallel, in some ways more direct, is William McDougall's (1908) approach to explaining motivated behavior in terms of instincts. Like proponents of memory systems, he took a perfectly respectable biological concept-instinct-and applied it to humans. He basically proposed that for each motivated human behavior there was an instinct responsible, and a correlated emotion. Some were straightforward; for eating, there is hunger. But others were less so. According to Boring (1950, p. 717), the list of instincts included flight, repulsion, curiosity, self-abasement, self-assertion, reproduction, gregariousness, and so forth, and each successive edition of McDougall's social psychology text included more. Boring writes that

this kind of dynamic psychology was popular because it was so simple and direct. It fell later in scientific disrepute, when psychologists discovered that anyone can make up his own list of instincts and that there is no way to prove that one list is more certainly correct than another. McDougall seemed to have borrowed too much from the faculty psychology of his Scottish ancestors ... who confused description with explanation. (p. 718)

It is, of course, too early to say whether or not the discovery of multiple memory systems will suffer the same fate as the proliferation of Gestalt laws, types of intelligence, and McDougall's hormic psychology, or will instead be vindicated like the increase in the number of known stars, galaxies, and black holes. The future debate should prove interesting.

\section{Closing Remarks}

These are exciting times for students of human memory. Variables that many of us had thought were relatively well understood, at least as to their empirical effects if not as to their theoretical interpretation, now behave quite differently on these new implicit measures of retention. Accounting for this state of affairs is the premier challenge confronting us now. The field is in ferment, in terms of terminology, findings, and theory. But that is good and exciting. I recently ran across a quote in a Lewis Thomas essay about biomedical research that seems to capture the contemporary state of affairs for students of implicit memory, and provides a fitting end to this comment.

The new mass of knowledge is still formless, incomplete; lacking the essential threads of connection, displaying mis- leading signals at every turn, riddled with blind alleys. There are fascinating ideas all over the place, irresistible experiments beyond numbering, all sorts of new ways into the maze of problems. But every next move is unpredictable, every outcome is uncertain. It is a puzzling time, but a very good time. (Thomas, 1974, p.119)

\section{REFERENCES}

Atkinson, R. C., \& Shiffrin, R. M. (1968). Human memory: A proposed system and its control processes. In K. W. Spence \& J. T. Spence (Eds.), The psychology of learning and motivation (Vol. 2, pp. 89-195). New York: Academic Press.

Biederman, I. (1987). Recognition-by-components: A theory of human image understanding. Psychological Review, 94, 115-147.

Biederman, I., Cooper, E. E., \& Gerhardstein, P. C. (1989, November). Priming fragmented images. Paper presented at the annual meeting of the Psychonomic Society, Atlanta.

Blaxton, T. A. (1989). Investigating dissociations among memory measures: Support for a transfer appropriate processing framework. Journal of Experimental Psychology: Learning, Memory, \& Cognition, 15, 657-668.

BorIng, E. G. (1950). A history of experimental psychology. New York: Appleton-Century-Crofts.

Cofer, C. N. (1967). Conditions for the use of verbal associations. Psychological Bulletin, 68, 1-12.

Ellis, A. W., \& Young, A. W. (1988). Human cognitive neuropsychology. Hillsdale, NJ: Erlbaum.

Gazzaniga, M. S. (1989). Organization of the human brain. Science, 245, 947-952.

Gick, M. L., \& Holyoak, K. J. (1983). Schema induction and analogical transfer. Cognitive Psychology, 14, 1-38.

Gollin, E. S. (1960). Developmental studies of visual recognition of incomplete objects. Perceptual \& Motor Skills, 11, 289-298.

Graf, P. C., \& MandLeR, G. (1984). Activation makes words more accessible, but not necessarily more retrievable. Journal of Verbal Learning \& Verbal Behavior, 23, 553-568.

GraF, P. C., Mandler, G., \& HAden, P. (1982). Simulating amnesic symptoms in normal subjects. Science, 218, 1243-1244.

GraF, P. C., \& SchaCter, D. L. (1985). Implicit and explicit memory for new associations in normal and amnesic subjects. Journal of Experimental Psychology: Learning, Memory, \& Cognition, 11, 386-396.

HeLSON, H. (1933). The fundamental propositions of Gestalt psychology. Psychological Review, 40, 13-32.

Hilgard, E. R. (1987). Psychology in America: A historical survey. San Diego: Harcourt Brace Jovanovich.

HolyoAK, K. J. (1985). The pragmatics of analogical transfer. In G. H. Bower (Ed.), The psychology of learning and motivation (Vol. 19, pp. 59-87). New York: Academic Press.

HovlaNd, C. I. (1951). Human learning and motivation. In S. S. Stevens (Ed.), Handbook of experimental psychology (pp. 613-689). New York: Wiley.

JACOBY, L. L. (1983). Remembering the data: Analyzing interactive processes in reading. Journal of Verbal Learning \& Verbal Behavior, $22,485-508$.

JACOBY, L. L. (1988). Memory observed and memory unobserved. In U. Neisser \& E. Winograd (Eds.), Remembering reconsidered: Ecological and traditional approaches to the study of memory (pp. 145177). Cambridge: Cambridge University Press.

JACOBY, L. L., \& BROOKs, L. R. (1984). Nonanalytic cognition: Memory, perception and concept learning. In G. H. Bower (Ed.), The psychology of learning and motivation (Vol. 18, pp. 1-47). New York: Academic Press.

JACOBY, L. L., \& DALLAS, M. (1981). On the relationship between autobiographical memory and perceptual learning. Journal of Experimental Psychology: General, 110, 306-340.

JACOBY, L. L., \& Kelley, C. M. (in press). An episodic view of motivation: Unconscious influences of memory. In E. T. Higgins \& R. M. Sorrentino (Eds.), Handbook of motivation and cognition (Vol. 2).

JACOBY, L. L., \& WiThERSPOON, D. (1982). Remembering without awareness. Canadian Journal of Psychology, 32, 300-324. 
Johnson, M. K., \& HASHER, L. (1987). Human learning and memory. Annual Review of Psychology, 38, 631-668.

LEEPER, R. (1935). A study of a neglected portion of the field of learning - the development of sensory organization. Jourmal of Genetic Psychology, 46, 41-75.

Lehman, D. R., Lempert, R. O., \& Nisbett, R. E. (1988). The effects of graduate training on reasoning. American Psychologist, 43, $431-442$.

LEWANDOWSKy, S., DUNN, J., \& KIRSNER, K. (1989). Implicit memory: Theoretical issues. Hillsdale, NJ: Erlbaum.

Lewicki, P., Czyzewska, M., Hoffman, H. (1987). Unconscious acquisition of complex procedural knowledge. Joumal of Experimental Psychology: Learning, Memory, \& Cognition, 13, 523-530.

Masson, M. E. J. (1989). Fluent reprocessing as an implicit expression of memory for experience. In S. Lewandowsky, J. C. Dunn, \& K. Kirsner (Eds.), Implicit memory: Theoretical issues (pp. 123-138). Hillsdale, NJ: Erlbaum.

MCDougall, W. (1908). Introduction to social psychology. London: Methuen.

NeEly, J. H. (1989). Experimental dissociations and the episodic/semantic memory distinction. In H. L. Roediger III \& F. I. M. Craik (Eds.), Varieties of memory and consciousness: Essays in honour of Endel Tulving (pp. 229-270). Hillsdale, NJ: Erlbaum.

NisBetT, R. E., \& WiLSON, T. D. (1977). Telling more than we can know: Verbal reports on mental processes. Psychological Review, 84, 231-259.

Nissen, M. J., \&ullemer, P. (1987). Attentional requirements of learning: Evidence from performance measures. Cognitive Psychology, 19, 1-32.

Olton, D. S. (1989). Inferring psychological dissociations from experimental dissociations: The temporal context of episodic memory. In H. L. Roediger III \& F. I. M. Craik (Eds.), Varieties of memory and consciousness: Essays in honour of Endel Tulving (pp. 161-177). Hillsdale, NJ: Erlbaum.

PaIvio, A. (1969). Mental imagery in associative learning and memory. Psychological Review, 76, 241-263.

Postman, L. (1971). Transfer, interference and forgetting. In J. W. Kling \& L. A. Riggs (Eds.), Experimental Psychology (pp. 10191132). New York: Holt, Rinehart and Winston.

REBER, A. S. (1967). Implicit learning of artificial grammars. Journal of Verbal Learning \& Verbal Behavior, 6, 855-863.

REBER, A. S. (1989). Implicit learning and tacit knowledge. Journal of Experimental Psychology: General, 118, 219-235.

Richardson-KLAVEhN, A., \& BJork, R. A. (1988). Measures of memory. Annual Review of Psychology, 39, 475-543.

RoEDIGER, H. L., III (1984). Does current evidence from dissociation experiments favor the episodic/semantic distinction? Behavioral \& Brain Sciences, 7, 252-254.

Roediger, H. L., III, Blaxton, T. A. (1987). Retrieval modes produce dissociations in memory for surface information In D. Gorfein \& R. R. Hoffman (Eds.), Memory and cognitive processes: The Ebbinghaus centennial conference (pp. 349-379). Hillsdale, NJ: Erlbaum.

RoEdiger, H. L., III, \& ChaLLis, B. H. (1990). Effects of identity repetition and conceptual repetition on free recall and word fragment completion. Manuscript in preparation.

Roediger, H. L., III, Rajaram, S., \& Srinivas, K. (in press). Specifying criteria for postulating memory systems. In A. Diamond (Ed.), Development and neural bases of higher cognitive function. New York: Annals of the New York Academy of Science.

Roediger, H. L., III, Weldon, M. S., \& Challis, B. H. (1989). Explaining dissociations between implicit and explicit measures of retention: A processing account. In H. L. Roediger III \& F. I. M. Craik (Eds.), Varieties of memory and consciousness: Essays in honour of Endel Tulving (pp. 3-41). Hillsdale, NJ: Erlbaum.

SCHACTER, D. L. (1987). Implicit memory: History and current status. Journal of Experimental Psychology: Learning, Memory, \& Cognition, 13, 501-518.

SCHACTER, D. L. (in press). Perceptual representation systems and implicit memory: Toward a resolution of the multiple memory systems debate. In A. Diamond (Ed.), Developmental and neural bases of higher cognitive function. New York: Annals of the New York Academy of Sciences.

SCHACTER, D. L., BoWERS, J., \& BOOKER, J. (1989). Intention, awareness, and implicit memory: The retrieval intentionality criterion. In S. Lewandowsky, J. C. Dunn, \& K. Kirsner (Eds.), Implicit memory: Theoretical issues (pp. 47-65). Hillsdale, NJ: Erlbaum.

SChacter, D. L., CoOper, L. A., \& Delaney, S. M. (1990). Implicit memory for unfamiliar objects depends on access to structural descriptions. Journal of Experimental Psychology: General, 119, 5-24.

SCHмIDT, R. A. (1988). Motor control and learning: A behavioral emphasis. Champaign, IL: Human Kinetics Press.

SEGAL, S. J. (1966). Priming compared to recall: Following multiple exposures and delay. Psychological Reports, 18, 615-620.

SHALLICE, T. (1988). From neuropsychology to mental structure. Cambridge: Cambridge University Press.

SherRy, D. F., \&ChaCTER, D. L. (1987). The evolution of multiple memory systems. Psychological Review, 94, 439-454.

Shoben, E. J., \& Ross, B. H. (1986). The crucial role of dissociations. Behavioral \& Brain Sciences, 9, 568-570.

Smith, E., \& Branscombe, N. (1988). Category accessibility as implicit memory. Journal of Experimental Social Psychology, 24, 490-504.

SNODGRASS, J. G. (1989). Sources of learning in the picture fragment completion task. In S. Lewandowsky, J. C. Dunn, \& K. Kirsner (Eds.), Implicit memory: Theoretical issues (pp. 259-282). Hillsdale, NJ: Erlbaum.

SQUIRE, L. R. (1987). Memory and brain. New York: Oxford University Press.

Srinivas, K., \& Roediger, H. L., III (in press). Classifying implicit memory tests: Category association and anagram solution. Journal of Memory \& Language.

SRULL, T. K., \&YER, R. S. (1980). Category accessibility and social perception: Some implications for the study of person memory and interpersonal judgments. Journal of Personality \& Social Psychology, 38, 841-856.

StADLER, M. A. (1989). On learning complex procedural knowledge. Journal of Experimental Psychology: Learning, Memory, \& Cognition, 15, 1061-1069.

STERNBerg, R. M. (1988). The triarchic mind. New York: Viking.

Tномаs, L. (1974). The lives of a cell: Notes of a biology watcher. New York: Viking.

Tulving, E. (1972). Episodic and semantic memory. In E. Tulving \& W. Donaldson (Eds.), Organization and memory (pp. 381-403). New York: Academic Press.

Tulving, E. (1983). Elements of episodic memory. New York: Oxford University Press.

Tulving, E. (1985). Memory and consciousness. Canadian Psychologist, 26, 1-12.

Tulving, E., \&Chacter, D. L. (1990). Priming and human memory systems. Science, 247, 301-305.

Tulving, E., Schacter, D. L., Stark, H. A. (1982). Priming effects in word-fragment completion are independent of recognition memory. Journal of Experimental Psychology: Learning, Memory, \& Cognition, 8, 336-342.

WARRINGTon, E. K., \& Weiskrantz, L. (1968). New method of testing long-term retention with special reference to amnesic patients. Nature, 217, 972-974.

Warrington, E. K., \& Weiskrantz, L. (1970). Amnesic syndrome: Consolidation or retrieval? Nature, 228, 629-630.

WeiskranTZ, L. (1987). Neuroanatomy of memory and amnesia: A case for multiple memory systems. Human Neurobiology, 6, 93-105.

WEISKRANTZ, L. (1989). Remembering dissociations. In H. L. Roediger III \& F. I. M. Craik (Eds.), Varieties of memory and consciousness: Essays in honour of Endel Tulving (pp. 101-120). Hillsdale, NJ: Erlbaum.

WELDON, M. S., \& RoEDIGER, H. L., III (1987). Altering retrieval demands reverses the picture superiority effect. Memory \& Cognition, 15, 269-280.

WITHERSPOON, D., \& Moscovitch, M. (1989). Stochastic independence between two implicit memory tasks. Journal of Experimental Psychology: Learning, Memory, \& Cognition, 15, 22-30. 


\section{NOTES}

1. The terms direct priming and repetition priming are often used synonymously, but a distinction between them can be observed. Repetition priming might be reserved for cases when the form of the presented item (e.g., a word) is the same on two occasions, as in the lexical decision task when the subject decides that elephant is a word twice and the faster reaction time on the second occasion provides the index of priming. Direct priming may be used whenever the target is the same on two occasions, even if its form is not (e.g., study elephant, test with _ _ $_{-}$ha $\_$_ $)$. Repetition priming may thus be viewed as a special case of direct priming, being limited to the situation when the exact form of the target is presented twice.

2. Fergus Craik made this point in the discussion following Schacter's presentation.

3. James Pomerantz pointed me to this example.

\section{Notices and Announcements}

\section{Publications Office Now Able to Accept Some Macintosh Disks}

To facilitate publication and to hold down costs, the Publications Office has expanded its capabilities in processing manuscripts accompanied by floppy disks, and we are pleased to announce that, in addition to all types of DOS disks, we now can accept Macintosh low-density 400K and 800K disks. Please note that we cannot use high-density Macintosh disks, and also that we are not yet able to process MacWrite files.

All disk files should be supplied in ASCII format. (ASCII is referred to by some word processing software as "nondocument" or "text-only" mode. See the software manual for more information.)

Detailed information will be supplied by the Editor's office upon acceptance of a manuscript. Feel free, nevertheless, to call the Publications Office for any further information needed (512-462-2442). 